\section{Breeding Cultivars from Blueberry $x$ Deerberry Hybrids: Progress and Prospects}

\author{
Paul M. Lyrene \\ Horticultural Sciences Department, University of Florida, Gainesville, FL \\ 32611
}

Additional index words. blueberry breeding, intersectional hybrids, introgression, tetraploid highbush blueberries, Vaccinium stamineum, wide hybridization

\begin{abstract}
Vaccinium stamineum (deerberry) is a highly variable diploid species in section Polycodium. Deerberry is native on excessively drained sandy soils from southeastern Ontario, south through the Florida peninsula to Lake Okeechobee, west to eastern Texas and southeastern Kansas. The $V$. stamineum used in this study were tall plants $(2-4 \mathrm{~m})$ native in north Florida, with a plant architecture similar to rabbiteye blueberry $(V$. virgatum). Starting in 2013 with crosses between tetraploid highbush cultivars (section Cyanococcus) and colchicine-doubled $V$. stamineum, hundreds of $F_{1}$ and thousands of later-generation seedlings were grown and evaluated in high-density field nurseries at Citra in North Florida. The populations studied included $F_{1}, F_{2}$, backcrosses to each parent species, and $\mathrm{BC}_{1} \times \mathrm{BC}_{1}$ seedlings. The goal of the study was to assess the feasibility of introgressing into highbush blueberry cultivars desirable traits from $\mathrm{V}$. stamineum (drought tolerance, red-flesh berries, new flavor components, open flowers with short corolla cups and exserted anthers and stigmas) without introducing horticulturally problematic characteristics (bitter skin, berries that shatter when ripe, difficult vegetative propagation). Vigor averaged very low in $F_{1}$ seedlings, higher in $F_{2}$ seedlings and in seedlings from backcrosses to $V$. stamineum, and highest in seedlings from backcrosses to highbush. Most crosses yielded numerous plump seeds, but crosses to produce $F_{1}$ hybrids yielded fewer than $10 \%$ as many seeds as highbush $\times$ highbush crosses. Most vegetative, flower, and fruit traits that differentiate highbush from $V$. stamineum were intermediate in $F_{1}$ seedlings. Backcross seedlings more closely resembled the recurrent parent. Variability in morphological characters was high in every generation, giving much opportunity for selection. Some seedlings from backcrosses to highbush $(\approx \mathbf{5 \%})$ appeared to have the vigor, berry quality, and yield potential required in commercial cultivars. Producing highbush cultivars that strongly express a particular $V$. stamineum trait might best be accomplished by growing large, segregating $F_{2}$ populations from which parents for backcrosses can be selected.
\end{abstract}

Cultivated highbush blueberries are clones that were developed by crosses involving Vaccinium section Cyanococcus species. Section Cyanococcus includes northern and southern highbush cultivars (complex hybrids based on $V$. corymbosum and related Cyanococcus species), lowbush (V. angustifolium), rabbiteye (V. virgatum), and various undomesticated diploid, tetraploid, and hexaploid species native in eastern North America.

The genus Vaccinium has wide distribution, with numerous native species in the tropical highlands of both the Old and New World. Vander Kloet (1997) divided the genus into 35 sections. Several sections, including Cyanococcus, include diploid, tetra-

Received for publication 3 Dec. 2020. Accepted for publication 15 Jan. 2021.

Published online 16 February 2021.

P.M.L. is the corresponding author. E-mail: Lyrene @ufl.edu.

This is an open access article distributed under the CC BY-NC-ND license (https://creativecommons. org/licenses/by-nc-nd/4.0/). the highbush blueberry cultivar Rancocas and tetraploid $V$. uliginosum (section Vaccinium; Rousi, 1963). The hybrids were fertile enough to allow the production of thousands of seedlings in backcrosses to tetraploid highbush. Some, but not all, tetraploid $\mathrm{F}_{1}$ hybrids between highbush cultivars and colchicine-produced $V$. arboreum (section Batodendron) were both male and female fertile (Lyrene, 2013). Tsuda et al. (2013) obtained fertile hybrids by crossing colchicineproduced tetraploids of the Japanese native blueberry ( $V$. bracteatum) with the highbush blueberry cultivar Spartan. Ehlenfeldt and Polashock (2014) reported fertile hybrids between highbush cultivars and tetraploid $V$. padifolium (section Hemimyrtillus). A selffertile $\mathrm{F}_{1}$ hybrid between $V$. corymbodendron (section Pyxothamnus) and diploid $V$. vitisidaea (section Vitis-idaea) was reported by Ehlenfeldt et al. (2018).

Vaccinium stamineum (deerberry) is the only species in Vaccinium section Polycodium, but it is highly polymorphic. Deerberries are endemic in North America and are found from southwestern Ontario to central Florida and west to eastern Texas (Vander Kloet, 1988). As noted by Vander Kloet (1988), Ballinger et al. (1979) found that deerberries resemble cranberries ( $V$. macrocarpon section Oxycoccus) more than blueberries (section Cyanococcus), not only in fresh-market and culinary qualities, but also in the types of anthocyanins and flavanols the berries contain. Deerberry plants in Florida are capable of maturing full crops of fruit in the forest, even under xeric conditions (Sharpe and Sherman, 1971). Ballington (1995) carefully studied large populations of $V$. stamineum in North Carolina and South Carolina, and concluded that deerberries had a high potential for domestication as a new crop.

Intersectional hybrids involving sections Cyanococcus and Polycodium have been reported previously. Coville produced viable diploid hybrids between $V$. stamineum and the diploid Cyanoccus species $V$. myrtilloides (Darrow and Camp, 1945). Uttal (1987) reported a natural hybrid between $V$. pallidum and $V$. stamineum. Several $\mathrm{F}_{2}$ hybrids from $V$. darrowii $\times V$. stamineum yielded tetraploid seedlings when crossed to tetraploid highbush in North Carolina (Ballington et al., 1997).

Tetraploid hybrids between highbush blueberry cultivars and colchicine-induced tetraploid $V$. stamineum have been reported previously (Lyrene, 2016, 2018). This article describes further progress in our efforts to recombine the genes of highbush cultivars and $V$. stamineum. The results of additional crosses involving $\mathrm{F}_{1}, \mathrm{~F}_{2}$, and backcross parents are given, along with a description of the phenotype of hybrid and backcross populations after several years in the field. Prospects for developing cultivars with novel characteristics, such as red flesh, adaptation to droughty soils, flowers that are accessible to a wider range of pollinating insects, and exotic new flavors, are discussed in light of 
what has been seen in hybrid and backcross populations.

\section{Materials and Methods}

Crossing and greenhouse procedures. All crosses were made in a bee-proof greenhouse between 2013 and 2020 using potted plants. The crosses were made to study the fertility and crossing behavior of various parental combinations and to produce seedlings for evaluation in the field. $\mathrm{BC}_{1}$ seedlings in this study were of two types, depending on whether the recurrent parent was highbush or tetraploid $V$. stamineum. Unless otherwise specified, $\mathrm{BC}_{1}$ hereafter refers to seedlings in which highbush was the recurrent parent, because they were most numerous and most extensively studied. Except in cases when the stigmas were far exserted from the corolla (e.g., in $V$. stamineum, some $\mathrm{F}_{1}$ hybrids, and $\mathrm{BC}_{1}$ seedlings when $V$. stamineum was the recurrent parent), the flowers on the seed parent were emasculated before anthesis; flowers not used in crosses were removed as they opened. Pollen was transferred to the stigmas by thumbnail. The $F_{1}$ plants used in crosses were selected from high-density field nurseries after examination throughout the year to make sure they were valid hybrids. Their identity as valid intersectional hybrids was confirmed by flower and inflorescence morphology when they flowered in the greenhouse (data not shown). As would be expected from intersectional hybrids, the hybrids were easily distinguishable from seedlings of the parental species after they flowered and fruited.

Unilateral cross compatibility has been reported in Vaccinium (Hiirsalmi, 1977; Wenslaff and Lyrene, 2003; Zeldin and McCown, 1997). Before 2019, all of our $F_{1}$ hybrids were produced using $V$. stamineum as the pollen parent. In 2019 and 2020, some crosses were made using tetraploid V. stamineum as the seed parent, and highbush cultivars or $F_{1}$ hybrids as pollen parents (Table 1). The reciprocal crosses were attempted to determine whether they would give seed and whether the seedling phenotype would differ, depending on the direction in which the cross was made.

Most crosses in which $V$. stamineum was the seed parent were made using secondgeneration tetraploid $V$. stamineum seedlings. These were produced by intercrossing tetraploid $V$. stamineum plants produced using colchicine. The advantages of using secondgeneration tetraploids were that they could easily be produced in large numbers and they avoided sectorial chimeras (some branches diploid, others tetraploid), which had been a problem with first-generation colchicine tetraploids (Lyrene, 2016). The $V$. stamineum plants used in the 2019 and 2020 crosses were confirmed as tetraploids based on pollen tetrad size. Both the flowers and the pollen tetrads from tetraploid plants were substantially larger than those from diploids (e.g., pollen tetrad diameters, typically 60 vs. $40 \mathrm{~nm})$.
An experiment was conducted in 2020 to test the possibility that selfing might have occurred while highbush pollen was being applied to the stigmas of unemasculated $V$. stamineum flowers. The experiment was conducted because a surprisingly large number of seeds had been obtained in 2019 by pollinating tetraploid $V$. stamineum stigmas with highbush or $F_{1}$ pollen. This raised the question of whether some second-generation tetraploid $V$. stamineum plants might be self-compatible, producing selfed seedlings rather than hybrids after highbush pollen was placed on the stigmas of unemasculated flowers. $V$. stamineum stigmas extend far beyond the anthers and the corolla, and highbush pollen was applied easily without emasculation. Although care was taken to avoid selfing while applying highbush pollen, some self-pollination could have occurred if the seed parents were selfcompatible. Diploid V. stamineum has been considered highly self-incompatible (Cane et al., 1985), but tetraploids have never been tested.

In the 2020 experiment, branches on each of seven tetraploid $V$. stamineum plants were divided into two groups. Flowers on some branches were pollinated with an abundance of self pollen, and those on others with an abundance of highbush pollen. None of the flowers was emasculated. Most of the flowers were pollinated multiple times over a period of a week or more.

Five crosses of a new type were attempted in 2020. Flowers of tetraploid $V$. stamineum were pollinated with pollen from tetraploid Vaccinium arboreum (section Batodendron). Like $V$. stamineum, V. arboreum (sparkleberry) is a diploid blueberry native in Florida and throughout the southeastern United States. Plants of the two species sometimes occur together in the forest, but $V$. stamineum normally flowers earlier and occurs on drier sites. Pollen used in these crosses was a composite from three colchicine-produced tetraploid $V$. arboreum plants that had been planted in a garden between 2005 and 2010 (Lyrene, 2011). The plants had previously been determined to be tetraploid by pollen size and stomate size, and by the production of large numbers of seedlings when crossed as pollen parent to tetraploid highbush cultivars (Lyrene, 2011). The branches from which the pollen was taken in 2020 were verified as tetraploid based on pollen size a few days before pollen was collected for use in crosses. V. stamineum flowers were pollinated over a period of 6 weeks starting in early Mar. 2020. Fresh $V$. arboreum pollen was collected from the garden for use each week.

Data gathered from the greenhouse. The number of flowers pollinated and the number of plump seeds obtained from each cross in 2019 and 2020 were recorded (Table 1). The first 10 berries that ripened from each cross were opened individually and the plump seeds in each berry were counted.

Various plant and berry characteristics were observed in the greenhouse on plants used as seed parents. Observed characteris- tics included flower and inflorescence morphology, plant vigor, berry size, berry color (wax, skin, and flesh), picking scar, stemminess, firmness, flavor, and tendency for berries to shatter when ripe.

Seed germination and planting of the field nurseries. The seeds from each cross were planted on the surface of peat in 4-L pots in a greenhouse in November of the year the cross was made. For crosses that produced large numbers of seed, only enough seeds were planted to provide at least 120 seedlings. During January and February (2-3 months after sowing the seed), young seedlings were transplanted to trays of peat. For crosses that produced numerous seedlings, no more than 120 seedlings were saved per cross. The seedlings were grown in the greenhouse for $\approx 3$ months.

Planting and evaluation of seedlings in the field nurseries. In May of each year, from 2015 through 2020, seedlings from the previous year's crosses were transplanted to a high-density field evaluation nursery at the University of Florida Plant Science Unit in Citra, FL (Table 2). The nurseries were prepared by mixing a $3-\mathrm{cm}$ layer of pine bark chips into the top $20 \mathrm{~cm}$ of the sandy soil. Seedlings were spaced $\approx 20 \mathrm{~cm}$ apart in rows that were $\approx 12 \mathrm{~m}$ long, with $45 \mathrm{~cm}$ between rows. The nurseries were irrigated with overhead irrigation and fertilized to maximize the growth of highbush blueberry seedlings planted in the same nursery. About 10,000 highbush and $400 \mathrm{~V}$. stamineum seedlings were planted along with the hybrids in each of the nurseries.

Each nursery was maintained for 4.3 years, allowing the seedlings in the older nurseries to be observed through four fruiting seasons. The nurseries were observed weekly throughout the year, and more frequently during the months of flowering and fruiting. The goal was to assess vigor, fruitfulness, and other characteristics of each type of seedling. During November, December, and January of each year, selected plants were dug, potted, and moved to the greenhouse for use as parents. Nighttime temperature in the greenhouse was kept above $5{ }^{\circ} \mathrm{C}$, but was otherwise allowed to vary with weather conditions, and fell to less than $10^{\circ} \mathrm{C}$ on many nights in December, January, and February. It was discovered that many $F_{1}$ plants that had no visible flower buds in the field nursery in early November and appeared to be too small and weak to flower the next spring, would flower if dug and potted in early November, chilled at $5{ }^{\circ} \mathrm{C}$ for 6 weeks in a dark cooler, and then moved to the greenhouse in late December. On most plants, flowers, sometimes numerous, were evident on the new leafy shoots that appeared from January through March.

Despite the close spacing of plants in the evaluation nurseries, vigor of $F_{1}$ hybrids and $\mathrm{BC}_{1}$ hybrids in which $V$. stamineum was the recurrent parent was so low that plants had enough space to grow and develop during 4 years in the nursery. $F_{1}$ populations were 
Table 1. Number of plump seeds produced by various types of controlled crosses in a greenhouse in 2019 and 2020.

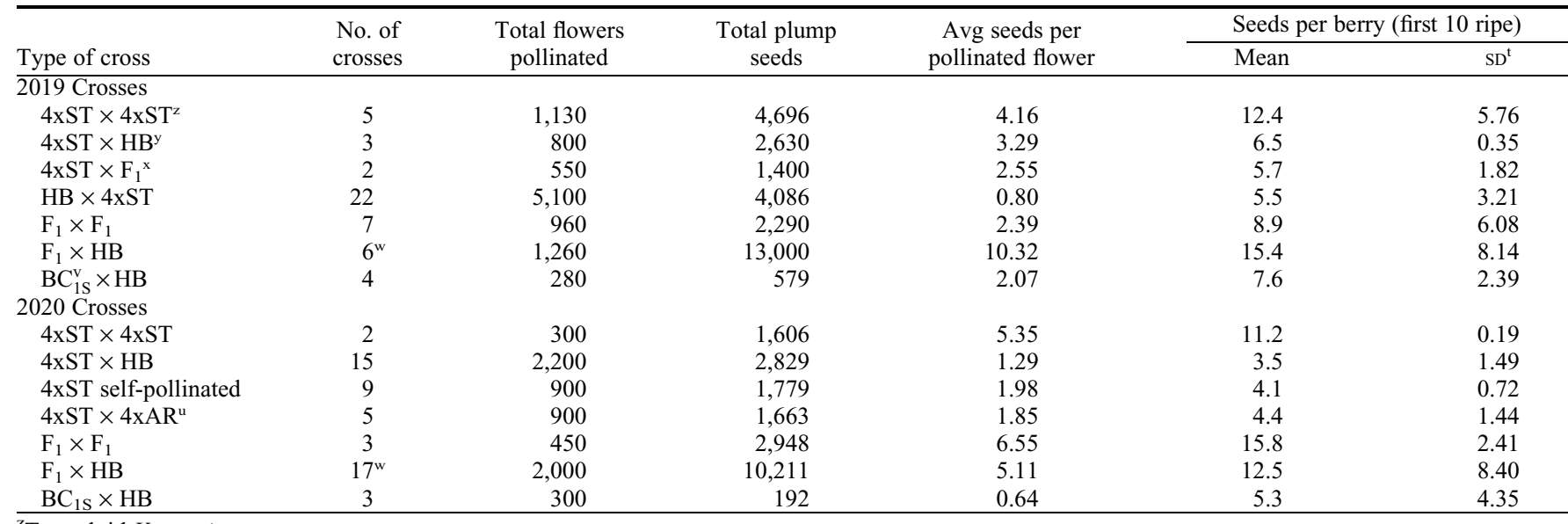

${ }^{\mathrm{z}}$ Tetraploid $V$. stamineum.

${ }^{\mathrm{y}}$ Tetraploid highbush cultivar.

${ }^{\mathrm{x}}$ Tetraploid hybrid from highbush cultivar $\times$ tetraploid $V$. stamineum.

${ }^{\mathrm{w}}$ In some of these crosses, $\mathrm{HB}$ was the seed parent; in others, the $\mathrm{F}_{1}$ was the seed parent. In all other crosses, the seed parent is stated first and the pollen parent second.

${ }^{\mathrm{v}}$ Backcross seedlings produced by pollinating $\mathrm{F}_{1}$ hybrids with pollen from tetraploid $V$. stamineum.

${ }^{\mathrm{u}}$ Tetraploid $V$. arboreum from colchicine treatment of seed.

t'Sample SD.

Table 2. Number of seedlings and number of crosses (in parentheses) for various types of highbush- $V$. stamineum hybrids planted in high-density field evaluation nurseries from 2014 to 2020.

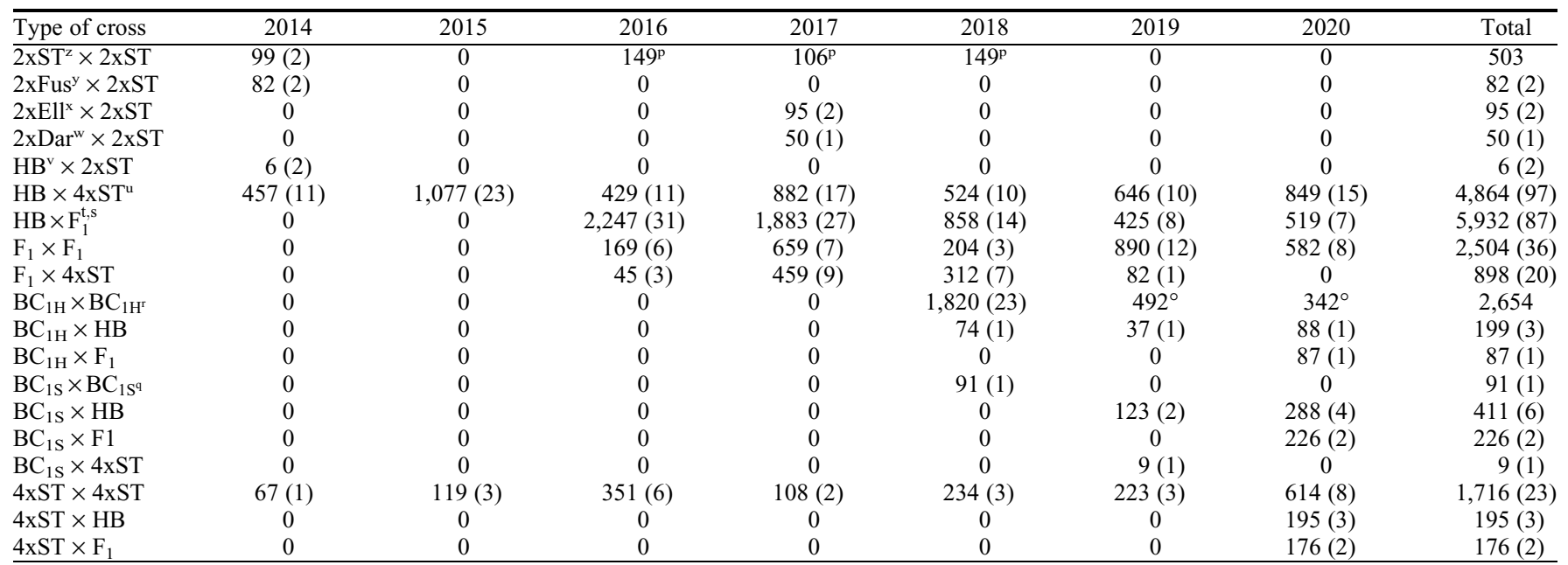

${ }^{\mathrm{z}}$ Diploid $V$. stamineum.

${ }^{\mathrm{y}}$ Diploid $V$. fuscatum from a forest near Frostproof, FL.

${ }^{\mathrm{x}}$ Diploid $V$. elliottii from southwestern Alabama.

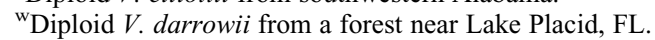

${ }^{\mathrm{v}}$ Tetraploid highbush cultivar.

${ }^{\text {uTetraploid } V \text {. stamineum. }}$

${ }^{t} \mathrm{~F} 1$ is the tetraploid hybrid from $\mathrm{HB} \times 4 \times \mathrm{xST}$.

${ }^{\mathrm{s}}$ In some of the crosses on this line, HB was the seed parent; in others, the $\mathrm{F}_{1}$ was the seed parent. In all other crosses, the seed parent is stated first and the pollen parent second.

${ }^{\mathrm{r}} \mathrm{F} 1 \times \mathrm{HB}$.

${ }^{\mathrm{q}} \mathrm{F} 1 \times 4 \mathrm{xST}$.

${ }^{\mathrm{p}}$ Grown from open-pollinated seed from the forest.

${ }^{\mathrm{o}} \mathrm{Seeds}$ from open pollination of $30 \mathrm{BC}_{1 \mathrm{H}}$ plants in an isolation block with no other pollen sources.

examined at the end of the first growing season to remove plants that did not appear to be the intended hybrids. This was necessary because highbush plants that appeared with the hybrids in some populations were so vigorous comparatively that they crowded out nearby $F_{1}$ plants after the second year in the nursery if not removed. In $\mathrm{BC}_{1}$ populations in which highbush was the recurrent parent, and in $\mathrm{BC}_{1} \times \mathrm{BC}_{1}$ populations, there was much variation in vigor, and after the first growing season in the field, competition among plants began to eliminate the weaker plants or prevent them from flowering. After the second year in the field nurseries, observations of fruit characteristics could only be made from the strongest, most competitive plants.

\section{Results and Discussion}

\section{Seed production from greenhouse} crosses

Most of the crosses made in the greenhouse in 2019 and 2020 produced numerous seeds (Table 1). Exceptions were highbush $\times$ tetraploid $V$. stamineum crosses and crosses in which one parent was a Backcross-1 of the 
Table 3. Production of plump seeds by seven tetraploid $V$. stamineum seedlings after self-pollination and after pollination with pollen from tetraploid highbush cultivars.

\begin{tabular}{|c|c|c|c|c|c|c|}
\hline \multirow[b]{2}{*}{$V$. stamineum female parent } & \multirow[b]{2}{*}{ Pollen parent } & \multirow[b]{2}{*}{ Flowers pollinated (n) } & \multirow[b]{2}{*}{ Fruit set $(\%)$} & \multirow[b]{2}{*}{ Seeds per pollinated flower } & \multicolumn{2}{|c|}{ Seeds per berry (first 10 ripe) } \\
\hline & & & & & Mean & $\mathrm{SD}^{\mathrm{y}}$ \\
\hline $20-519$ & $12-179 \mathrm{HB}^{\mathrm{x}}$ & 120 & 8 & 0.30 & 3.00 & 1.76 \\
\hline $18-726$ & Selfed & 70 & 59 & 1.24 & 4.70 & $2.64^{v}$ \\
\hline $20-518$ & Selfed & 120 & 69 & 1.12 & 3.59 & $2.26^{\mathrm{v}}$ \\
\hline $20-518$ & 05-185 HB & 110 & 45 & 0.59 & 2.12 & 1.70 \\
\hline $18-727$ & Selfed & 70 & 69 & 1.36 & 3.09 & $2.15 \mathrm{NS}^{\mathrm{w}}$ \\
\hline $20-501$ & Kestrel HB & 40 & 30 & 1.20 & 5.60 & 3.84 \\
\hline $20-505$ & Selfed & 200 & 28 & 5.36 & 4.75 & $1.65 \mathrm{NS}^{\mathrm{w}}$ \\
\hline $20-505$ & Emerald HB & 200 & 24 & 4.40 & 5.10 & 1.77 \\
\hline $20-513$ & Selfed & 100 & 64 & 1.36 & 3.40 & $2.28 \mathrm{NS}^{\mathrm{w}}$ \\
\hline $20-513$ & 13-143 HB & 120 & 78 & 0.94 & 2.62 & 1.69 \\
\hline
\end{tabular}

${ }^{\mathrm{z}}$ Pairwise $t$ tests were done to compare mean number of seeds per berry in the first 10 ripe berries when each female was selfed or pollinated with highbush cultivar pollen.

${ }^{\mathrm{y}}$ Sample SD.

${ }^{\mathrm{x}}$ Tetraploid highbush cultivar.

${ }^{\text {w}}$ The means did not differ at $P=5 \%$.

${ }^{v}$ The means differed at $P=5 \%$.

NS $=$ not significant.

type (highbush $\times V$. stamineum) $\times V$. stamineum. Similar crosses had given low seed numbers in previous years (Lyrene, 2016, 2018; and unpublished).

In the 2020 experiment, which involved seven tetraploid $V$. stamineum plants used as female parents, both self-pollinated flowers and flowers that received highbush pollen produced berries and seeds (Table 3). On most $V$. stamineum females, the number of seeds obtained did not differ significantly for the selfed and crossed branches. This suggests that most of the seedlings from the highbush pollen were true hybrids, not seedlings from selfpollination. Had most of the seedlings from crossed flowers been the result of unintended self-pollination, more seed would have been expected from flowers that were intentionally self-pollinated with an abundance of pollen than from flowers where efforts were made to avoid self-pollination and highbush pollen was applied in abundance. Both the selfed and the intersectional pollinations gave fewer seeds than crosses between tetraploid $V$. stamineum genotypes (Table 1), suggesting that partial self-incompatibility reduced seed production from self-pollinated flowers, and intersectional incompatibility reduced seed production from flowers pollinated with highbush pollen.

After one growing season in the field, most seedlings from the $V$. stamineum $\times$ highbush and $V$. stamineum $\times \mathrm{F}_{1}$ crosses made in 2019 had phenotypes consistent with their hybrid origins. Seedlings for which $\mathrm{F}_{1}$ hybrids had been the pollen parent were more vigorous than those with highbush as the pollen parent. This would not be expected if seedlings from both types of pollinations had resulted from selfing.

\section{Evaluation of horticultural characters in the field nursery}

Vigor. Except for having larger flowers, second-generation tetraploid $V$. stamineum seedlings were similar to diploids in vigor and macroscopic morphology. Both were as vigorous as seedlings from highbush $\times$ highbush crosses growing in the same nursery.

Crosses in which a diploid section Cyanococcus species (V. darrowii, V. elliotti, and $V$. fuscatum were tried) was the seed parent and diploid $V$. stamineum was the pollen parent gave numerous hybrid seedlings, but these were invariably very weak. Some of these seedlings probably would have survived to flower had they been potted and placed in a greenhouse, but this was not attempted.

With rare exceptions, $F_{1}$ hybrids obtained by crossing tetraploid highbush cultivars with tetraploid $V$. stamineum were far weaker than either parent (Fig. 1). $F_{1}$ hybrids varied greatly in vigor depending on the particular highbush and $V$. stamineum plants that were crossed. Sibling seedlings within some crosses were highly variable in vigor, but in other crosses all the seedlings were very weak. About half the $F_{1}$ seedlings from the most vigorous half of the crosses could probably have been brought to flowering if potted and grown in a greenhouse. When the strongest $F_{1}$ plants were dug, potted, and placed in the greenhouse, most of them increased in vigor but remained less vigorous than highbush seedlings. The weakness of the $F_{1}$ hybrids in the high-density field nurseries was probably a result, in part, to excess soil moisture. Overhead irrigation scheduling was adjusted to maximize the growth of highbush seedlings planted in other parts of the same nursery. These were far more vigorous and required much more water than the hybrids. Year after year, $F_{1}$ seedlings were much more susceptible to leaf mites (Eotetranychus clitus) in the greenhouse than either parent growing in the same greenhouse. To prevent defoliation, it was necessary to control mites. Of the original four tetraploid $V$. stamineum plants used repeatedly in crosses, FL13-1145 consistently

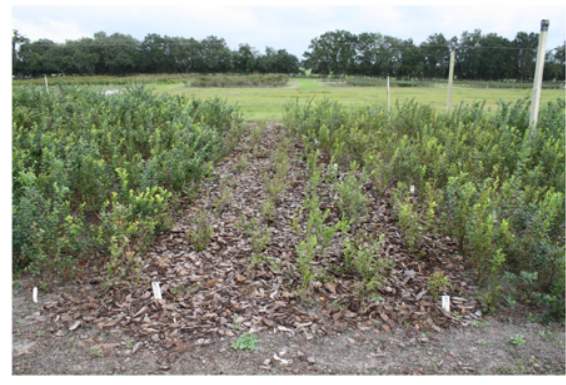

Fig. 1. Seedlings in the 2019 high-density nursery photographed 22 Oct. 2020. The nursery was planted 30 May 2019 using greenhouse-grown seedlings from seed planted in Nov. 2018. The four weakest rows in the center contain $F_{1}$ hybrids from highbush $\times$ tetraploid $V$. stamineum crosses. The more vigorous rows on the left contain seedlings obtained by intercrossing $\mathrm{BC}_{1}$ seedlings that had $V$. stamineum as the recurrent parent, and those on the right contain $\mathrm{F}_{2}$ seedlings from $\mathrm{F}_{1} \times \mathrm{F}_{1}$ crosses.

produced the most vigorous $F_{1}$ seedlings, although nothing about its appearance distinguished it as special.

$\mathrm{F}_{2}$ seedlings, produced by intercrossing unrelated $F_{1}$ hybrids, were much more vigorous than $F_{1}$ seedlings (Fig. 1). In part, this was probably because only the strongest $F_{1}$ plants were used as parents, but gametic and zygotic selection were also probably important, because only the most functional gametes from the $F_{1}$ parents were likely to make zygotes and only the most functional zygotes were likely to make viable seed.

$A n$ additional increase in vigor was seen in $\mathrm{BC}_{1}$ seedlings if highbush was the recurrent parent. Like $\mathrm{F}_{1}$ seedlings, $\mathrm{BC}_{1}$ seedlings were highly variable in vigor, both within and between crosses. Only about $10 \%$ of the thousands of $\mathrm{BC}_{1}$ seedlings grown in the field for 3 years or more appeared to be as vigorous as typical highbush seedlings. Poor 
leaf health, resulting from diseases and physiological disorders, was one reason for the weakness of many seedlings. Seedlings from $\mathrm{BC}_{1} \times \mathrm{BC}_{1}$ crosses were no more vigorous than seedlings of the parent generation, and vigor continued to be highly dependent on which particular plants served as parents.

$\mathrm{BC}_{1}$ seedlings from crosses in which $V$. stamineum was the recurrent parent were less vigorous than those with highbush as the recurrent parent, but they were extremely variable in vigor. About $30 \%$ of these seedlings, after three growing seasons in the field, had medium vigor and healthy leaves. The $V$. stamineum backcross seedlings were more vigorous and looked more like $V$. stamineum than the most vigorous $\mathrm{F}_{1}$ plants. In growth habit and vegetative appearance, the $\mathrm{BC}_{1}$ seedlings were very distinct from $V$. stamineum. In the field, some of the plants flowered profusely but produced little fruit. This may have been the result of low male or female fertility and the fact that they flowered late, when little pollen was available from other tetraploid blueberries growing nearby. Several of the $\mathrm{BC}_{1}$-to- $V$. stamineum seedlings produced defective flowers in which the styles were missing or poorly developed.

In the 2019 greenhouse, four V. stamineum backcross seedlings that were pollinated with highbush pollen produced berries of the expected phenotype (more like deerberries than blueberries) and made a considerable amount of seed (Table 1). Seedlings from these four crosses were substantially more vigorous than most highbush $\times V$. stamineum $\mathrm{F}_{1}$ hybrids, and their leaves had a healthier green color.

Plant architecture. The deerberry plants used as parents resembled highbush blueberries in plant architecture (crown forming, with 2-10 major canes arising from a small base, reaching a height of 2-3 $\mathrm{m}$ after several years in field nurseries). Except for low vigor, the bush structure of the $F_{1}$ hybrids resembled the parents. Seedlings from backcrosses to highbush generally resembled highbush in architecture. After 3 years in the field, a few $\mathrm{F}_{2}$ and backcross seedlings (especially those with $V$. stamineum as the recurrent parent) produced upright canes bearing large numbers of short, stiff side branches oriented perpendicular to the upright canes. These seemed analogous to fruiting spurs in apricots, almonds, apples, and pears. Branches of this kind are rare in highbush and not common in deerberry. The apical $65 \mathrm{~cm}$ of one vigorous, upright cane on a $\mathrm{BC}_{1}$ plant examined in November bore 50 spurlike branches (Fig. 2). These spurs were stiff, woody, and 2 to $6 \mathrm{~cm}$ long. Each had four to six nodes, with a bud at each node. The previous May, several canes on the plant shown in Fig. 2 had produced clusters of ripe berries extending basipetally from the apex for 40 to $60 \mathrm{~cm}$ on the major canes, giving the appearance of cattail (Typha) spikes.

Fertility. Most tetraploid V. stamineum plants were highly fertile, whether they had been produced by colchicine treatment or by intercrossing colchicine-derived tetraploids.
An exception was FL13-872, which was widely used as a pollen parent because it was one of the first tetraploids available, in which only about half of the microspores appeared to be normal under the microscope at $\times 250$ magnification. $F_{1}$ hybrids varied widely in fertility (Lyrene, 2016). The most vigorous seedlings obtained by backcrossing $F_{1}$ hybrids to highbush were typically very fruitful and produced berries with numerous seeds when open-pollinated in the field. An open-pollinated polycross involving $25 \mathrm{BC}_{1}$ plants in $15-\mathrm{L}$ pots placed outside of the greenhouse, in which the only pollen source was other $\mathrm{BC}_{1}$ hybrids, produced an abundance of berries, and these contained numerous well-developed seeds. The increased fertility in the $\mathrm{BC}_{1}$ population compared with the $F_{1}$ was probably a result, in part, of the use of the most fertile $F_{1}$ plants as parents and, in part, to gametic and zygotic selection for increased fertility.

Ease of vegetative propagation. Highbush blueberry cultivars are clones, propagated by stem cuttings or in vitro. V. stamineum of the type used in this study (2-4 m tall with a few stout canes) is nearly impossible to propagate from stem cuttings except using highly juvenile cuttings. Juvenile cuttings are not available from plants that have been selected for superior fruit. Juvenile shoots suitable for rooting in a mist propagation bed can be produced in vitro from mature plants of $V$. stamineum (Lubell and Brand, 2018; A. Garcia, personal communication), but efficient methods for producing field-ready plants from $V$. stamineum microcuttings need to be developed. Nonjuvenile softwood cuttings of most $F_{1}$ hybrids rooted readily under mist, but cuttings of others did not (Lyrene, 2016). Cuttings from some hybrids fail to root because they defoliate quickly when placed under mist, but cuttings from other hybrids maintain healthy leaves for several months under mist but do not form roots. Some seedlings from backcrosses to highbush are also slow to root from stem cuttings.

Ripening date. The highbush cultivars used in the crosses ripen from $10 \mathrm{Apr}$. through 15 May when grown in the field in North Florida. Berries on the diploid $V$. stamineum plants from which the tetraploids

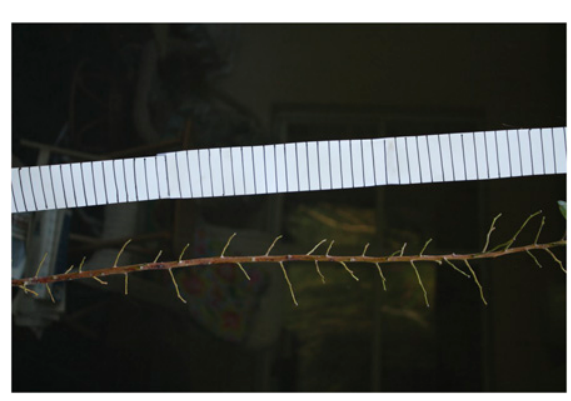

Fig. 2. Spurlike branches on an upright cane of a $\mathrm{BC}_{1}$ seedling (highbush the recurrent parent) transplanted to the field nursery in May 2017. Photographed 4 Nov. 2020. The scale is in centimeters. were derived ripen in the forest in North Florida from late June through late July. $\mathrm{BC}_{1}$ seedlings with highbush as the recurrent parent typically ripened 3 to 4 weeks later than highbush cultivars when the two were grown together in field plots at the research station at Citra, FL, but there was much variation among the $\mathrm{BC}_{1}$ seedlings. $\mathrm{BC}_{1}$ hybrids that have a low-chill requirement but late flowering and ripening might be used to extend the blueberry harvest season in low-chill production areas. In Florida, late flowering decreases losses from freezes but increases problems with flower thrips, which often destroy late flowers and prevent pollination.

Inflorescence, raceme, and flower structure. Highbush flowers are borne on short peduncles that do not persist after the berries are harvested. Flowers and berries on some cultivars are tightly clustered. Tight berry clusters can become a problem as berry size is increased through breeding. In $V$. stamineum, both the pedicels and peduncles are much longer, with much more space between the berries. In $\mathrm{F}_{1}$ and $\mathrm{BC}_{1}$ hybrids, peduncle and pedicel length range widely between the parental types, but the racemes of most hybrids are more open than in highbush (Figs. 3-5).

Flowers of blueberry species in section Cyanococcus are adapted to buzz pollination by native bees such as Bombus and

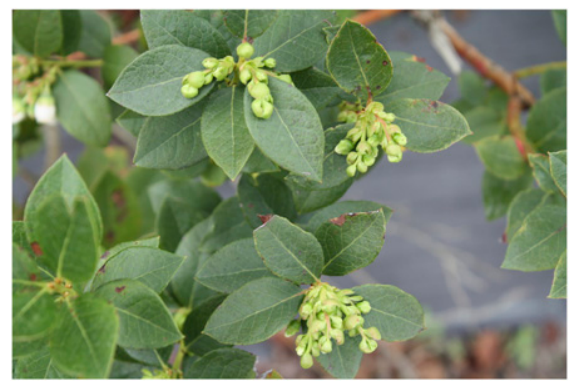

Fig. 3. $\mathrm{BC}_{1}$ seedlings with inflorescence structure intermediate between that of highbush and $V$. stamineum. Peduncles elongate well before the flowers open. Photographed 22 Oct. 2020.

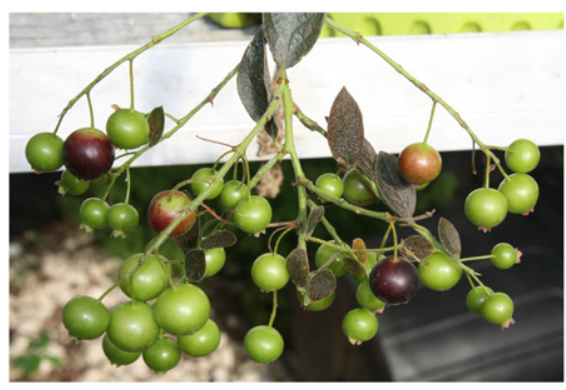

Fig. 4. Clusters of berries on an $F_{1}$ hybrid in the greenhouse showing long pedicels and peduncles. The flowers had been pollinated with pollen from a highbush cultivar. The plant had been defoliated by mites during berry development. 


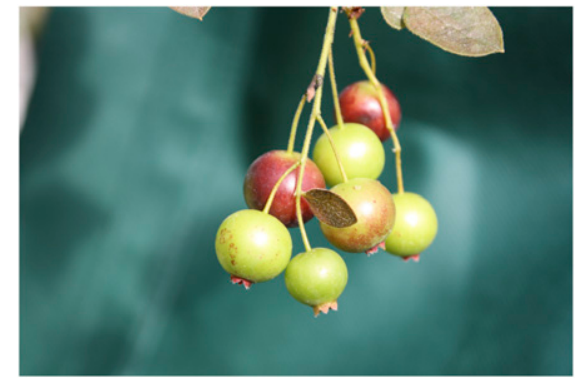

Fig. 5. Loose clusters of berries on an $F_{1}$ hybrid in the greenhouse after the flowers had been pollinated with pollen from a highbush cultivar.

Habropoda. Achieving adequate pollination using honeybees has been a problem for growers in commercial blueberry plantations in Florida and Georgia. Flowers of most highbush cultivars have a long corolla tube, which has a constricted aperture and anthers located well inside the tube. By contrast, in $V$. stamineum, the corolla cup is short, with a wide opening, and both the stigma and anthers extend well beyond the end of the corolla cup (Cane et al., 1985). The pollen and stigmas are readily accessible to honeybees and other nonsonicating pollinators. Flower structure in $F_{1}$ and $F_{2}$ hybrids was surprisingly variable. All $\mathrm{F}_{1}$ plants had flower morphology somewhere between that of the parents; but, in some, flowers were more like those of $V$. stamineum and, in others, more like those of highbush. Flowers on both $F_{1}$ and $\mathrm{BC}_{1}$ plants tended to be smaller than on highbush. Flowers of all $F_{1}$ plants had anther awns, which are absent in highbush and conspicuous in $V$. stamineum, but these were invariably smaller than in $V$. stamineum. Flower structure remained quite variable in $\mathrm{BC}_{1}$ (to highbush) hybrids, and plants could be selected in which the pollen is readily accessible to honeybees. In many $\mathrm{BC}_{1}$ hybrids, the pollen discharge tubes extend all the way to the stigma, and both are near the aperture of the corolla tube. In highbush flowers, the anthers are situated deep inside the corolla tube.

Berry size. Deerberries in the forest are larger than those of any other wild North American Vaccinium species (Fig. 6). Mean weight of 100 individually weighed berries selected randomly from each of three heavily loaded $V$. stamineum plants in the forest in Alachua County, FL, on 8 July 2020 were $1.24,1.37$, and $1.15 \mathrm{~g}$, respectively, with SEMS of $0.057,0.035$, and 0.023 . Mean berry weight for 23 wild tetraploid highbush blueberry plants ( $V$. fuscatum) from Alachua County, FL, ranged from 0.14 to $0.54 \mathrm{~g}$, with an overall mean for the 23 plants of $0.25 \mathrm{~g}$ (Lyrene and Sherman, 1980). Berries of the highbush cultivars grown in Florida are large because of 6 to 10 generations of selection for large berries. Berries on the most vigorous and fertile $\mathrm{BC}_{1}$ plants averaged about as large as berries from random seedlings from highbush $\times$ highbush cultivar crosses, indicating that $V$. stamineum introgression had not reduced berry size.

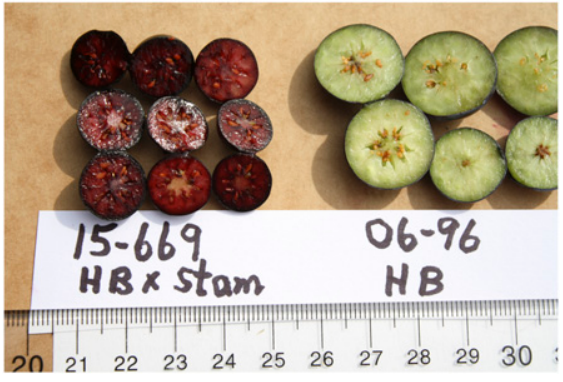

Fig. 6. Internal berry color of freshly sliced mature berries of tetraploid selection FL 15-669 (a highbush cultivar $\times$ tetraploid $V$. stamineum $\mathrm{F}_{1}$ hybrid) and highbush cultivar FL06-96.

Berry color. Ripe berries from highbush cultivars typically have black skin, green to white flesh, and variable amounts of surface wax that gives the berries of some varieties a powdery blue appearance. Mature berries from the wild $V$. stamineum plants used in this study had skin that was black after the surface wax was removed. Because of variations in berry-surface waxes, mature $V$. stamineum berries in the forest ranged from shiny black to powdery blue depending on the plant.

Unlike the section Cyanococcus species and the cultivars bred from them, V. stamineum is polymorphic for flesh color. About half the plants in the forest from which our parents came had a flesh color of whitegreen, like that of highbush, and about half had flesh color ranging from light pink through bright red to dark purple. These colors were consistent over years on individual plants, some of which have been observed yearly for 8 years or more. The tetraploid $V$. stamineum plants used in this study were obtained by colchicine treatment of seeds or seedlings with a flesh color that was unknown at the time of colchicine treatment. By chance, two of the first four tetraploid plants used in crosses had pink to red flesh in fully ripe berries.

Some $\mathrm{F}_{1}$ hybrids had pink to red flesh (Fig. 6; Lyrene, 2016). The $F_{1}$ plants used in backcrosses were selected for vigor and fertility, without regard to flesh color. The berry flesh of some $\mathrm{BC}_{1}$ plants in the field was somewhat pink, but the pink was less intense than in the pigmented $F_{1}$ hybrids and only appeared in berries that were fully mature. Mature berries from numerous $\mathrm{BC}_{1}$ plants were compared with those from numerous highbush seedlings growing in the same nursery. Pink flesh was much more common among seedlings in the $\mathrm{BC}_{1}$ populations. None of the $\mathrm{BC}_{1}$ plants had enough pigment to be considered commercially purple fleshed. A project to obtain highbush-type cultivars with deep-red flesh should start with the selection of $V$. stamineum parents having the most intense purple flesh, because the character is extremely variable in $V$. stamineum.

When extracting seeds from crosses, it was noticed that a 50:50 (by volume) mix of water and fresh berries homogenized in a

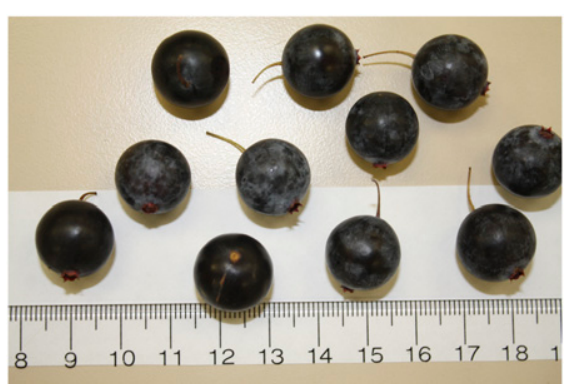

Fig. 7. Large berries from a diploid plant of $V$. stamineum (clone FL15-695) harvested from a forest in Alachua County, FL, July 2015. Pedicels remain attached to the berries when they abscise from the peduncle. The scale is in centimeters.

food blender produced a puree that was normally much brighter red with $\mathrm{F}_{1}$ and $\mathrm{BC}_{1}$ berries than with highbush berries. When berries from wild diploid $V$. stamineum plants were processed in the same way, the puree was bright red, even if the berries had white-green flesh. These bright colors were stable for more than a week at room temperature. The difference between highbush and $V$. stamineum puree pigment intensity may be a result of the thicker skin of $V$. stamineum berries or a greater pigment concentration in the skin.

Berry scar, stemminess, and shattering. When highbush blueberries ripen, an abscission zone forms between the berry and the pedicel, and harvested berries are free of pedicels (i.e., they are not stemmy). In $V$. stamineum, the abscission zone is at the opposite end of the pedicel, and the berries come off the bush with the pedicel attached (Fig. 7). The $F_{1}$ hybrids tended to be intermediate, with much variation from plant to plant. Most $\mathrm{BC}_{1}$ plants resembled highbush in stem separation, and the berries were mostly not stemmy. In wild highbush and in some of the earlier released cultivars, the skin tended to tear when the berry was separated from the pedicel. These cultivars were said to have a bad scar. In $V$. stamineum, the pedicel is long and very thin compared with highbush. When the pedicels are forcibly removed from the berries, only a small scar is formed. The scar on most $\mathrm{BC}_{1}$ plants was small and dry.

The diploid $V$. stamineum population from which the parents came was polymorphic for berry shattering. Some plants that seemed to be loaded with berries at the start of the ripening season never held a large number of ripe berries, because the berries fell as they ripened. On only $20 \%$ to $30 \%$ of the plants were most of the ripe berries retained long enough on the bush so the plant appeared, at some time, to be loaded with ripe fruit. Berry shattering was highly variable among both the first- and second-generation tetraploid $V$. stamineum plants. Most $\mathrm{F}_{1}$ and $\mathrm{F}_{2}$ seedlings and nearly all backcross seedlings held their berries well, but shattering was a problem with a few. 
Flavor. Four aspects seemed variable in $\mathrm{F}_{1}$ populations: sugar, acidity, bitterness, and the presence of aromatic or spicey flavors not found in section Cyanococcus species. Deerberries in the source population had high Brix. Ten plants growing in the forest whose average Brix was determined using a hand refractometer on 16 July 2020 (stated as the average of three single-berry samples per plant), and ranged from 15.0 to $22.0^{\circ}$ Brix. Typical values for cultivated highbush range from 13 to $16{ }^{\circ}$ Brix (DeGraw et al., 2016). Acidity was not measured but, by taste, ranged from low to medium compared with the average for highbush cultivars. Berries of $V$. stamineum are sometimes stated in the literature to be inedible or barely edible because of their astringency or bitterness. In our deerberry source population, berries never seemed astringent, but ranged from slightly bitter to strongly bitter. Bitterness seemed to be concentrated in the skin and was less noticeable in the flesh. Bitterness was not detected in the berries of any $\mathrm{BC}_{1}$ plants in which highbush was the recurrent parent. The berries of some $\mathrm{F}_{2}$ and $\mathrm{BC}_{1}$ plants had pleasant aromatic or spicey flavors not found in section Cyanococcus species. Deerberries from the forest, when dried at room temperature and stored for 3 months without refrigeration, were sweet, somewhat bitter, and had a flavor component suggestive of pine.

Texture. V. stamineum seeds are slightly larger than those of highbush, but the berries are large and juicy and do not seem more gritty than highbush berries. Deerberries have thick skin. This gives the berries a pleasant "pop" or crunch when eaten, but the skin residues that persist during chewing sometimes elicit complaints. Thick skin did not seem problematic in the $\mathrm{BC}_{1}$ plants.

Potential postharvest qualities. No formal studies were done, but deerberries held in paper bags at room temperature for $10 \mathrm{~d}$ seemed to stay firm without shriveling or becoming moldy just as well as the best highbush cultivars. Berries collected from the ground beneath the plants in the forest remain firm for a week or more after they fall.

\section{Difficulties encountered when trying to derive cultivars from highbush $\times V$. stamineum hybrid populations}

Obtaining plants that meet the collective requirements of growers, marketers, and consumers starting with weak intersectional hybrids will not be easy. It was not hard to get hybrid seedlings by crossing highbush cultivars with tetraploid $V$. stamineum plants. Many (but not all) of the tetraploid $\mathrm{F}_{1}$ hybrids had surprisingly high fertility and fruitfulness, and, in some cases, high berry quality, but nearly all of them were weak, and many were susceptible to disease, insect, and physiological problems. In September, October, and December, when highbush cultivars often make their best growth in Florida, $V$. stamineum plants in the forest are often losing their leaves. In October, in high-density nurseries, the foliage on many (but not all) $\mathrm{F}_{2}$ and $\mathrm{BC}_{1}$ seedlings appeared less healthy than on highbush seedlings. In the greenhouse, defoliation by leaf mites was much more severe on $F_{1}$ blueberry-deerberry hybrids than on the parent taxa.

Fall flowering was a problem with some $V$. stamineum-highbush advanced-generation hybrids. Fall flowering in North Florida usually results in loss of berries resulting from winter freezes, and berries that ripen in early winter can have high acidity and low sugar contents. Many hybrids that lost flowers and berries from winter freezes still produced numerous berries in the spring because of the flower buds that remained dormant until late winter.

A problem in the introgression program has been the occasional appearance of highbush plants and plants of unknown origin among the $F_{1}$ seedling populations. Because large numbers of flowers must be pollinated to generate relatively few $F_{1}$ hybrids, even a low level of self-pollination can produce a substantial percentage of nonhybrid plants. Even with careful emasculation and removal of all unpollinated flowers from female parents in the greenhouse, some nonhybrid plants appeared in some populations of hybrid seedlings. In the high-density field evaluation nursery, these plants were almost always far more vigorous than the $F_{1}$ hybrids. Because of the close spacing of the plants, a single highbush plant could overshadow and kill several true hybrids. It was necessary to identify and remove nonhybrid plants from the nursery before the second growing season. On rare occasions, a plant appeared among the $F_{1}$ seedlings that resembled highbush in most aspects, but seemed to have one or more traits that could only have come from $V$. stamineum. These anomalous seedlings are a puzzle, but southern highbush cultivars have a complex genetic background, and it is not always safe to conclude that a particular seedling with surprising characteristics could not be a highbush seedling.

\section{Summary and Outlook}

The phenotypic variation observed indicates that commercial cultivars could probably be selected from seedlings in $\mathrm{BC}_{1}$ or $\mathrm{BC}_{2}$ populations following highbush $\times V$. stamineum crosses. In addition to the characters already discussed, several useful traits might be obtained in highbush cultivars using genes from $V$. stamineum. Improved drought tolerance is likely to be found in the hybrids. Deerberries grow naturally on excessively drained, coarse-textured upland sands; highbush are native on moist flatwoods soils where peat accumulates.

Cultivars with a flower structure that makes the pollen readily accessible to honeybees could be selected. The ability to flower on new spring growth flushes rather than from overwintering flower buds formed the previous autumn might be useful in some environments. Highbush blueberries that lose their leaves prematurely in the fall as a result of insects, leaf diseases, hurricanes, or other causes, form few flower buds, and few flowers open in the spring. During winter, highbush flower buds can be damaged by freezes, blueberry bud mites, or gall midges. In Florida forests, $V$. stamineum normally begins to defoliate early in the fall as a result of insects, diseases, drought, low soil nutrients, and genetic factors. No flower buds are visible on $V$. stamineum in January, but the plants can still flower heavily 3 months later and produce heavy berry crops on the spring growth flushes. Many of the $F_{1}$ hybrids appeared to have inherited the ability to form flowers on spring growth flushes even when no flower buds could be seen in midwinter.

In addition to adaptation to excessively drained mineral soils, open flower structure, and red flesh, $V$. stamineum could be the source of various nutraceutical compounds, such as iridoids. Iridoids are secondary metabolites, present in various plant families, that may exhibit a range of pharmacological activities, such as cardiovascular, hypoglycemic, anti-inflammatory, hepatoprotective, antimutagenic, antispasmodic, antitumoral, antiviral, immunomodulatory, and purgative effects (Viljoen et al., 2012). Plants that produce iridoids have a history of use in traditional medicine in treating inflammatory conditions (Viljoen et al., 2012). Leisner et al. (2017) measured iridoid content in the berries of 84 Vaccinium accessions, including many Cyanococcus cultivars and several wild species from other sections. Of the 71 Cyanococcus cultivars sampled, 'Ozarkblue' had the greatest iridoid content measured as monotropein (113 ng. $\mathrm{mg}^{-1}$ dry fruit weight). Of the non-Cyanococcus species sampled, $V$. stamineum had the greatest content of monotropein $\left(2371 \mathrm{ng} \cdot \mathrm{mg}^{-1}\right.$ berry dry weight $)$, and $V$. arboreum had $1692 \mathrm{ng} \cdot \mathrm{mg}^{-1}$. If iridoids can contribute to human health, both $V$. stamineum and $V$. arboreum could serve as gene sources for increasing iridoids in highbush cultivars.

In attempting to move single traits, such as red flesh, wide-open flowers, or exotic flavors, from $V$. stamineum into highbush cultivars, growing large $\mathrm{F}_{2}$ populations might be the key to success. $F_{2}$ seedlings are relatively easy to produce in large numbers, and the plants are much more vigorous than $F_{1}$ seedlings. $F_{2}$ seedlings are vigorous and fertile enough to be evaluated for plant and fruit characteristics in high-density field nurseries. $\mathrm{F}_{2}$ seedlings are extremely variable for many of the traits that distinguish highbush and $V$. stamineum. This high variability indicates that at least some homoeologous chromosome pairing is occurring in the $F_{1}$ hybrids (Ramsey and Ramsey, 2014). To minimize inbreeding and maximize diversity, the $F_{1}$ parents should be chosen so that every $F_{2}$ seedling has four distinct genotypes as grandparents. Superior $F_{2}$ seedlings can be used in backcrosses to produce cultivars.

\section{Literature Cited}

Ballinger, W.E., G.J. Galletta, and E.P. Maness. 1979. Anthocyanins of fruits of Vaccinium subgenera Cyanococcus and Polycodium. J. Amer. Soc. Hort. Sci. 104:554-557. 
Ballington, J.R. 1995. The deerberry (Vaccinium stamineum L. Vaccinium section Polycodium (Raf.) Sleumer): A potential new small fruit crop, p. 21-28. In: R.E. Gough and R.F. Korcak (eds.). Blueberries: A century of research. Haworth Press, Inc., New York, NY, doi: 10.1300/J065v03n02 03.

Ballington, J.R., S.D. Rooks, W.O. Cline, J.R. Meyer, and R.D. Milholland. 1997. The North Carolina State University blueberry breeding program: Toward $V$. $\times$ covilleanum? Acta Hort. 446:243-250, doi: 10.17660/ActaHortic. 1997.446.36.

Cane, J.H., G.C. Eickwort, F.R. Wesley, and J. Spielholz. 1985. Pollination ecology of Vaccinium stamineum (Ericaceae: Vaccinioideae). Amer. J. Bot. 72:135-142, doi: 10.1002/j.15372197.1985.tb05351.x.

Darrow, G.M. and W.H. Camp. 1945. Vaccinium hybrids and the development of new horticultural material. Bull. Torrey Bot. Club 72:121.

DeGraw, C., S. Watkinson, and L. DeVetter. 2016. Highbush blueberry cultivar trial in northwestern Washington. Whatcom Ag Monthly 5(9). 8 Feb. 2021. <https://extension.wsu.edu/wam/past-issues2016/>.

Ehlenfeldt, M.K. and J.J. Polashock. 2014. Highly fertile intersectional blueberry hybrids of $\mathrm{Vac}$ cinium padifolium section Hemimyrtillus and V. corymbosum section Cyanococcus. J. Amer. Soc. Hort. Sci. 139:30-38, doi: 10.21273/ JASH.139.1.30.

Ehlenfeldt, M.K., J.J. Polashock, and J.R. Ballington. 2018. Vaccinium corymbodendron Dunal as a bridge between taxonomic sections and ploidies in Vaccinium: A work in progress. North American Blueberry Research and Extension Workers Conference: 15. 8 Feb. 2021. <https:// digitalcommons.library.umaine.deu/nabrew2018/ proceedingpapers/proceedingpapers/15>.
Hiirsalmi, H. 1977. Inheritance of characters in hybrids of Vaccinium uliginosum and highbush blueberries. Ann. Agr. Fenn. 16:7-18.

Leisner, C.P., M.O. Kamileen, M.E. Conway, S.E. O'Connor, and R. Buell. 2017. Differential iridoid production as revealed by a diversity panel of 84 cultivated and wild blueberry species. PLoS One, doi: 10.1371/journal.pone.0179417.

Lubell, J. and M. Brand. 2018. Softwood cutting propagation and micropropagation of deerberry (Vaccinium stamineum). Native Plants J. 10:216223, doi: $10.3368 /$ npj.19.3.216.

Lyrene, P.M. 2011. First report of Vaccinium arboreum hybrids with cultivated highbush blueberry. HortScience 46:563-566, doi: 10.21273/ HORTSCI.46.4.563.

Lyrene, P.M. 2013. Fertility and other characteristics of $F_{1}$ and backcross ${ }_{1}$ progeny from an intersectional blueberry cross ((highbush cultivar $\times$ Vaccinium arboreum $) \times$ highbush cultivar). HortScience 48:146-149, doi: 10.21273/ HORTSCI.48.2.146.

Lyrene, P.M. 2016. Phenotype and fertility of intersectional hybrids between tetraploid highbush blueberry and colchicine-treated $\mathrm{Vacci}$ nium stamineum. HortScience 51:15-22, doi: 10.21273/HORTSCI.51.1.15.

Lyrene, P.M. 2018. Hybridization of cultivated highbush blueberry with Vaccinium stamineum: Phenotype and fertility of backcross populations. HortScience 53:159-166, doi: 10.21273/HORTSCI.12650-17.

Lyrene, P.M. and W.B. Sherman. 1980. Horticultural characteristics of native Vaccinium darrowii, V. elliottii, V. fuscatum, and V. myrsinites in Alachua County, Florida. J. Amer. Soc. Hort. Sci. 105:393-396.

Ramsey, J. and T.S. Ramsey. 2014. Ecological studies of polyploidy in the 100 years following its discovery. Phil. Trans. R. Soc. Britain. 369: 20130352, doi: 10.1098/rstb.2013.0352.
Ritchie, J.C. 1955. A natural hybrid in Vaccinium I: The structure, performance and chorology of the cross Vaccinium intermedium Ruthe. New Phytol. 54:49-67, doi: 10.1111/j.14698137.1955.tb06157.x.

Rousi, A. 1963. Hybridization between Vaccinium uliginosum and cultivated blueberry. Ann. Agr. Fenn. 2:12-18.

Rousi, A. 1966. Cytological observations on some species and hybrids of Vaccinium. Der Zuchter 36:352-359, doi: 10.1007/BF00631138.

Sharpe, R.H. and W.B. Sherman. 1971. Breeding blueberries for low chilling requirement. HortScience 6:145-147.

Tsuda, H., H. Kunitake, M. Yamasaki, H. Komatsu, and K. Yoshioka. 2013. Production of intersectional hybrids between colchicine-induced tetraploid Shashanbo (Vaccinium bracteatum) and highbush blueberry 'Spartan'. J. Amer. Soc. Hort. Sci. 138:317-324, doi: 10.21273/JASHS.138.4.317.

Uttal, L.J. 1987. The genus Vaccinium L. (Ericaceae) in Virginia. Castanea 52:231-255.

Vander Kloet, S.P. 1988. The genus Vaccinium in North America. Pub. 1828, Agriculture Canada.

Vander Kloet, S.P. 1997. The nature and variation of dichotomous characters in Vaccinium L. Amer. J. Bot. 84(6) (Supplement to p. 239) (abstr.).

Viljoen, A., N. Mncwangi, and I. Vermaak. 2012. Anti-inflammatory iridoids of botanical origin. Curr. Med. Chem. 19:2104-2127, doi: 10.2174/ 092986712800229005.

Wenslaff, T. and P. Lyrene. 2003. Unilateral cross compatibility in Vaccinium elliottii $\times V$. arboreum, an intersectional blueberry hybrid. Euphytica 131:255-258, doi: 10.1023/A:1024034219248.

Zeldin, E.L. and B.H. McCown. 1997. Intersectional hybrids of lingonberry (Vaccinium vitis-idaea, section Oxycoccus) and cranberry (V. macrocarpon, section Oxycoccus) to Vaccinium reticulatum (section Macropelma). Acta Hort. 446:235-238, doi: 10.17660/ActaHortic.1997.446.34. 